\title{
Clamshell thoracotomy for en bloc resection of a 3-level thoracic chordoma: technical note and operative video
}

\author{
John F. Burke, MD, PhD, ${ }^{1}$ Andrew K. Chan, MD, ${ }^{1}$ Rory R. Mayer, MD, ${ }^{1}$ Joseph H. Garcia, BS, ${ }^{2}$ \\ Brenton Pennicooke, MD, ${ }^{1}$ Michael Mann, MD, ${ }^{3}$ Sigurd H. Berven, MD, ${ }^{4}$ Dean Chou, MD, ${ }^{1}$ and \\ Praveen V. Mummaneni, MD'
}

1Department of Neurological Surgery, ${ }^{2}$ School of Medicine, ${ }^{3}$ Department of Surgery, Division of Adult Cardiothoracic Surgery, and ${ }^{4}$ Department of Orthopedic Surgery, University of California, San Francisco, California

\begin{abstract}
The clamshell thoracotomy is often used to access both hemithoraxes and the mediastinum simultaneously for cardiothoracic pathology, but this technique is rarely used for the excision of spinal tumors. We describe the use of a clamshell thoracotomy for en bloc excision of a 3-level upper thoracic chordoma in a 20 -year-old patient. The lesion involved T2, T3, and T4, and it invaded both chest cavities and indented the mediastinum. After 2 biopsies to confirm the diagnosis, the patient underwent a posterior spinal fusion followed by bilateral clamshell thoracotomy for 3-level en bloc resection with simultaneous access to both chest cavities and the mediastinum. To demonstrate how the clamshell thoracotomy was used to facilitate the tumor resection, an operative video and illustrations are provided, which show in detail how the clamshell thoracotomy can be used to access both hemithoraxes and the mediastinum.
\end{abstract}

https://thejns.org/doi/abs/10.3171/2020.6.FOCUS20382

KEYWORDS chordoma; en bloc resection; clamshell thoracotomy; operative video; surgical technique

$\mathrm{C}$ HORDOMAS are malignant spinal neoplasms arising from notochordal remnants and most frequently occur in the clivus and sacral spine..$^{-3}$ Within the mobile spine (C1-L5), chordomas most commonly occur in the cervical and lumbar levels; it is rare for a chordoma to occur in the thoracic spine, especially the upper thoracic spine. ${ }^{4}$ Boriani et al. presented 52 consecutive cases of chordomas in the mobile spine over a 50-year period, and only 1 tumor arose from the upper thoracic spine (T4) in an adult patient. ${ }^{5}$ In 2012, Fontes and O'Toole reviewed the literature and found only 22 reported cases of thoracic chordomas. ${ }^{4}$ Moreover, chordomas usually appear after age 40 years and are rare in young adults and pediatric patients. ${ }^{1}$ When chordomas do occur in pediatric patients, they occur almost exclusively along the clivus. ${ }^{6}$

En bloc excision of thoracic chordoma can require an anterior approach, but this strategy usually involves either a standard thoracotomy or a sternotomy. When the tumor invades both chest cavities and the mediastinum, a clamshell thoracotomy can be employed to access all 3 anterior compartments simultaneously. We describe the use of the clamshell thoracotomy to excise a 3-level upper thoracic chordoma. We present the case of a 20 -year-old female pa- tient with a 3-level thoracic chordoma that invaded both chest cavities and indented the mediastinum. Because of the upper thoracic spine location and because of the invasion into both chest cavities by the tumor, a formal clamshell thoracotomy was performed to achieve an en bloc excision. The description of the approach presented here includes illustrations and a video.

\section{Methods}

\section{History, Workup, and Surgical Planning}

A 20-year-old otherwise healthy woman presented with shortness of breath and wheezing. Chest radiograph revealed an $8-\mathrm{cm}$ left eccentric mediastinal mass. Standing scoliosis radiographs, cervicothoracic spine $\mathrm{CT}$, and total spine MRI with and without contrast were obtained. An MRI neurogram was also obtained to evaluate possible involvement of the left brachial plexus, but the evaluation results were negative. Imaging revealed an enhancing lesion involving the T2-4 vertebral bodies and expanding predominantly into the left hemithorax, right hemithorax, and mediastinum (Fig. 1). The tumor was indenting the anterior upper mediastinal structures, including the great 

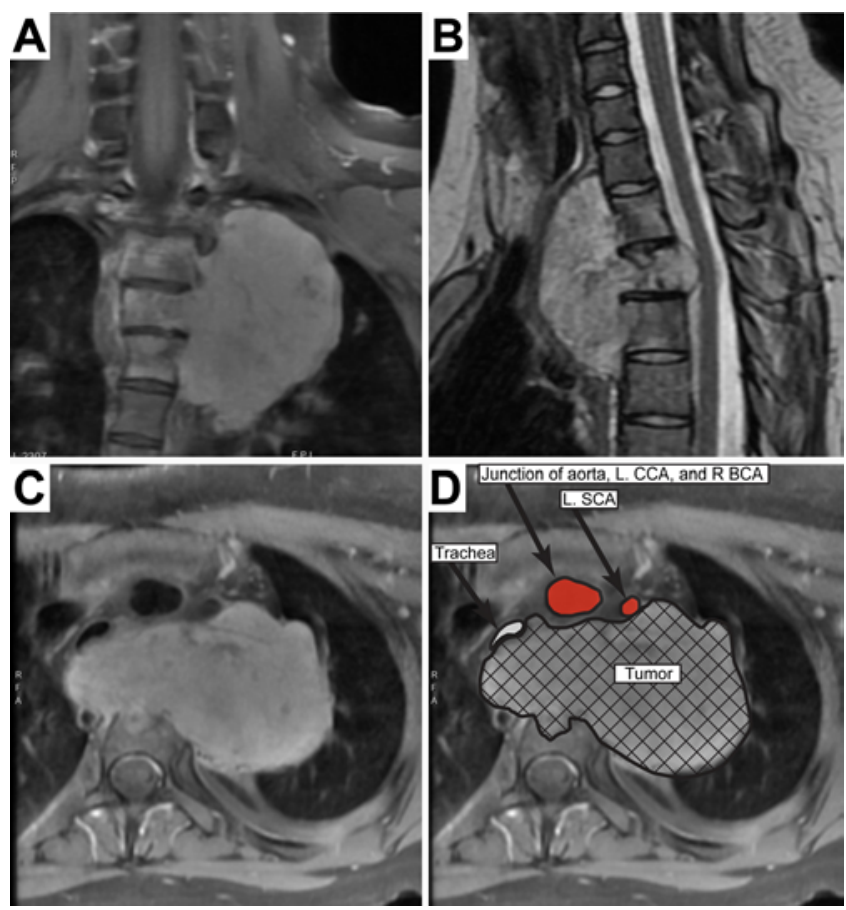

FIG. 1. Preoperative MRI of the tumor. Coronal (A), sagittal (B), and axial (C) contrast MR images of the tumor. D: The axial MRI is shown with vital structures highlighted, including the trachea, the junction of the aorta with the left common carotid artery (L. CCA) and right brachiocephalic artery (R BCA), and the left subclavian artery (L. SCA).

vessels, esophagus, and trachea, but there was no radiographic evidence of invasion of these structures (Fig. 1D). The radiographic findings were consistent with a thoracic chordoma. The patient underwent a CT-guided biopsy to establish the diagnosis, which was determined to be chordoma. Because of the atypical presentation in a 20 -yearold patient, a repeat CT-guided biopsy was performed, again confirming the diagnosis of chordoma. Once the diagnosis of chordoma was confirmed by pathological analysis, en bloc resection was planned. The invasion into both chest cavities and the mediastinum made removing the chordoma entirely from a posterior-only approach too risky for possible spinal cord damage and intralesional violation. Moreover, the upper thoracic spine poses unique access obstacles not only because of the kyphotic nature of the spine in this area, but also because the mediastinum and the innominate vein are essentially immobile. Thus, a standard median sternotomy would not have sufficed. In addition, because the tumor was in both chest cavities and the mediastinum, a clamshell thoracotomy was planned to access both chest cavities and the mediastinum simultaneously.

\section{Operative Technique}

The plan was to first perform posterior stabilization with release of the posterior elements and sacrifice of the involved nerve roots, followed by 3-level en bloc excision from the anterior approach. In the posterior approach, instrumentation was performed from $\mathrm{C} 5$ to $\mathrm{T} 8$, a T1-5 laminectomy was performed, and $\mathrm{T} 1-2$ and $\mathrm{T} 4-5$
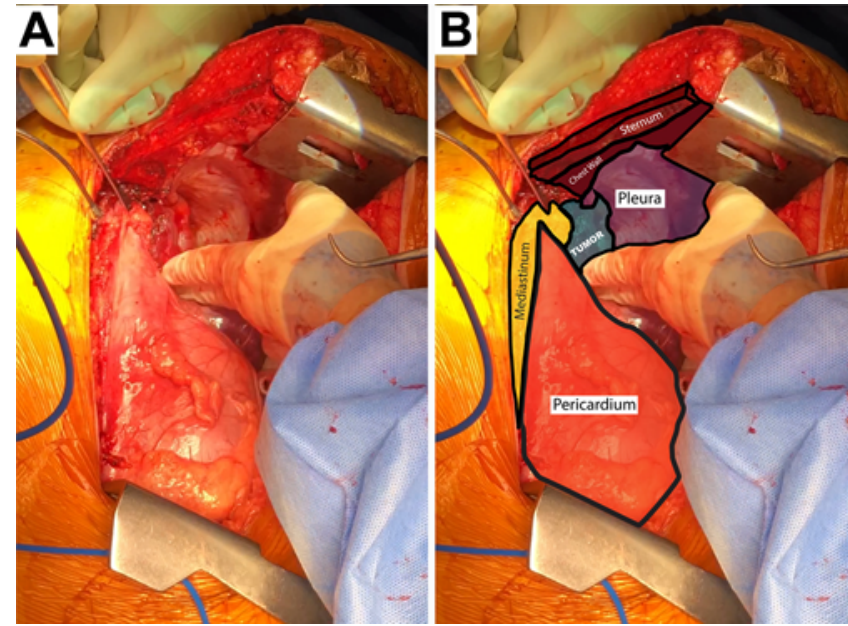

FIG. 2. Left-sided thoracotomy and tumor exposure. A: The first leftsided thoracotomy is shown with exposure of the pericardium, mediastinum, tumor, pleura, chest wall, and sternum. B: These structures are labeled for orientation.

discectomies were completed. The left-sided T2, T3, and T4 nerve roots were sacrificed to enable en bloc resection during the second stage. In order to release the dorsal spine from the ventral tumor, the entire posterior elements were removed at T2, T3, and T4, including the pedicles, the transverse processes, and the facets. Posterior element resection was correlated with tumor extension by MRI; posterior element excision was carried out until a definite margin between normal bone and tumor was ensured by continual cross referencing the MRI intraoperatively. In addition, the biopsy tract was included and excised during the posterior stage.

Although the patient had consented to a complete clamshell thoracotomy, the second stage was begun with a leftsided hemiclamshell thoracotomy by thoracic surgery to expose the tumor as well as the pericardium and pleural space. Specifically, the surgical saw was used to vertically divide the sternum in the midline, and then to extend the sternotomy laterally at the level of the fifth interspace. Chest wall retractors were placed to expose the upper left hemithorax, and the tumor was identified (Fig. 2). The left lung was found to be free of any significant attachments to the tumor. The left subclavian artery, the innominate vein and artery, and the arch of the aorta were dissected away from the tumor. The posterior parietal pleura was scored circumferentially around the tumor and was dissected toward the midline. Attempts were made to dissect beneath the anterior mediastinum to reach the tumor in the right thoracic cavity; however, adequate exposure and visualization of the right tumor margin could not be achieved because of the mediastinal structures. Therefore, the thoracotomy was extended into a bilateral hemiclamshell thoracotomy to expose the right-sided aspect of the tumor and spine (Fig. 3A and B).

The sternum was divided laterally at the level of the fourth interspace. The right anterior chest wall was then similarly retracted, and complete exposure of the right aspect of the T2 through T4 tumor and vertebral bodies 

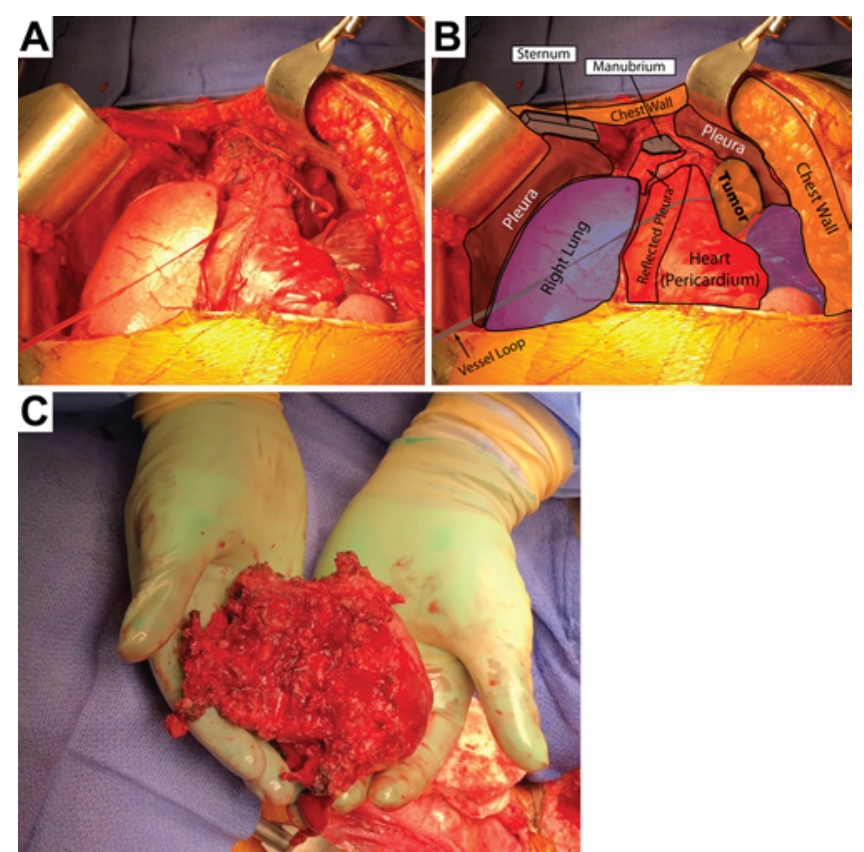

FIG. 3. Bilateral thoracotomy and en bloc tumor resection. A: The bilateral thoracotomy. B: Several structures are labeled, including the pleura, the right lung, the pericardium, the tumor, and the chest wall. C: The tumor after en bloc resection.

was achieved. Once the tumor was completely exposed, the anterior longitudinal ligament and residual annulus at T1-2 and T4-5 was resected to release the T2, T3, and T4 vertebral bodies. The tumor was then dissected off the pleura on the posterior chest wall. After complete dissection laterally, the T2, T3, and T4 vertebral bodies were excised in an en bloc fashion (Fig. 3C and Video 1).

VIDEO 1. Intraoperative video of the bilateral clamshell thoracotomy for en bloc resection of 3-level thoracic chordoma. Copyright UCSF

Department of Neurological Surgery. Published with permission.

Click here to view.

To reconstruct the anterior column, an expandable cage filled with rib autograft was then placed under intraoperative fluoroscopy. The bilateral hemiclamshell thoracotomy was closed by thoracic surgery in the standard fashion. Postoperative radiographs show that the instrumentation was in a good position (Fig. 4A and B). Radiographs of the resected tumor show the vertebral bodies resected with the tumor, verifying en bloc resection (Fig. 4C and D). Pathological analysis showed a neoplasm invading bone and soft tissues composed of bland epithelioid cells with eosinophilic cytoplasm and occasional cells with cytoplasmic vacuolations, arranged in cords and trabeculae in a background of myxoid matrix. Neoplastic cells stained positive for epithelial membrane antigen, S-100, pancytokeratin, and brachyury, consistent with a diagnosis of chordoma. There was a marginal margin against the dura, and the patient was referred for proton beam radiation. Two months after surgery, the patient experienced a 3-4$\mathrm{cm}$ wound breakdown of the incision inferior to the right breast, which was revised by thoracic surgery. The patient was placed on oral antibiotics and recovered well. At the

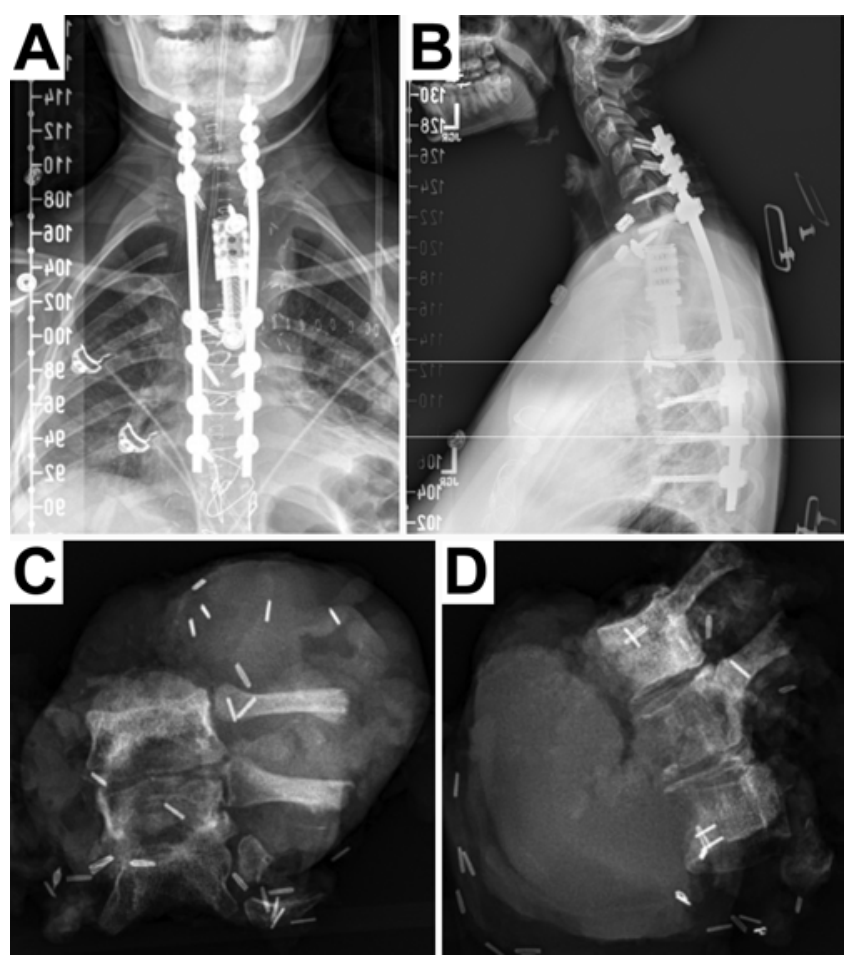

FIG. 4. Postoperative radiographs. Postoperative anterior-posterior (A) and lateral (B) radiographs of the instrumentation, as well as radiographs of the resected tumor (C and D).

5-month follow-up, the incision was well healed, motor strength was at least 4+/5 in the arms and legs (assessed over telehealth), and there was residual dysesthesia in the patient's left arm radiating to her left fifth digit.

\section{Discussion}

Thoracic chordomas are very uncommon and represent an estimated $1 \%$ of all chordomas. ${ }^{4}$ Although these tumors tend to arise at a much earlier age than other chordomas, our 20-year-old patient was still well below the mean age of presentation (37.5 years). ${ }^{2}$ Early diagnosis of thoracic chordomas is generally difficult because of lack of specific symptoms. ${ }^{6,7}$ The time from onset of symptoms to diagnosis is almost always more than 8 months. ${ }^{8,9}$ MRI is the radiological gold standard for diagnosis and surgical planning. These tumors are isointense to hypointense on T1-weighted MRI, with variable enhancement. On T2weighted MRI, chordomas are hyperintense but may have some heterogeneity in signal intensity because of calcification and bony sequestration.

En bloc excision of chordomas is currently the most effective way to prevent local recurrence..$^{10,11}$ Although en bloc resection was completed in this case, it is often difficult to achieve en bloc excision without significant morbidity. Moreover, chordomas are considered radioresistant, rendering most radiation therapies ineffective. ${ }^{12}$ Chemotherapy is for the most part ineffective. En bloc resection during the initial surgery gives the best chance to achieve long-term local control. According to comprehensive population-based studies, the median overall survival 


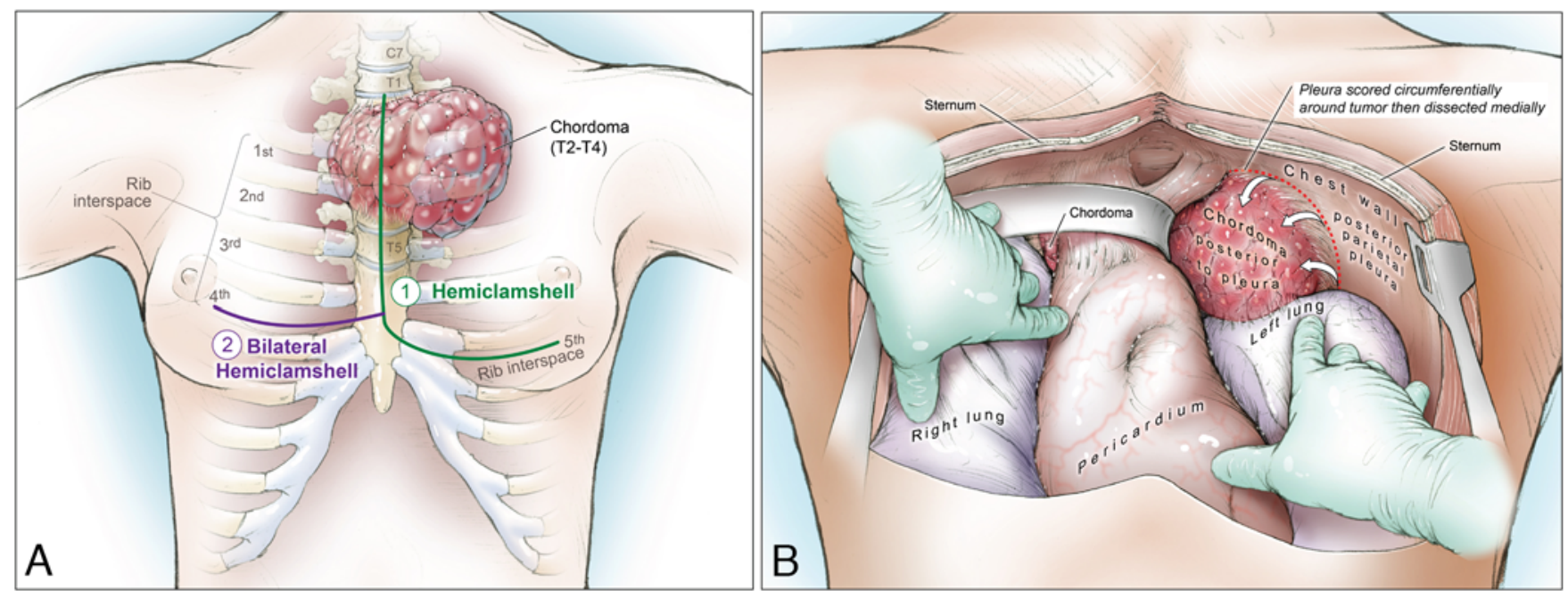

FIG. 5. Illustration of the bilateral hemiclamshell thoracotomy. A: Sequence of bony cuts employed in this case. B: Overall exposure afforded by the bilateral hemiclamshell thoracotomy. Copyright Kenneth Probst. Published with permission.

for chordoma patients is just over 7 years, and the overall 5 - and 10 -year survival rates are $68 \%$, and $40 \%$ respectively. ${ }^{12,13}$

The clamshell thoracotomy was first described by Kortz in 1958, who used a transverse thoracosternotomy. ${ }^{14}$ The procedure was further developed and popularized for bilateral lung transplantations by the Washington University group. ${ }^{15,16}$ Although the midline sternotomy had been previously described for this purpose, ${ }^{17,18}$ the bilateral clamshell thoracotomy (referred to as a "cross-bow" thoracotomy at the time) was favored because it provided superior access to the left and right pleural spaces, as well as the posterior mediastinum. ${ }^{15,18}$ Since these initial descriptions, the procedure has been modified to include the unilateral "hemiclamshell" thoracotomy, ${ }^{19,20}$ as well as the sternum-sparing variant in which a transverse sternotomy is avoided. ${ }^{21}$ Although the indications and relative advantages of the median sternotomy versus the bilateral clamshell approach for cardiopulmonary transplantation are still debated, ${ }^{22,23}$ the principal advantage of the bilateral clamshell thoracotomy is superior exposure of both pleural spaces with simultaneous bilateral access to the posterior mediastinum. ${ }^{15,23,24}$ The clamshell thoracotomy is therefore indicated when wide exposure of these structures is necessary, and it has been used for a variety of purposes, such as repair of cardiac defects ${ }^{25}$ and treatment of infection, ${ }^{26}$ pulmonary metastatic lesions, ${ }^{19}$ traumatic conditions requiring emergent thoracic access, ${ }^{27}$ and approaches to large intrathoracic tumors. ${ }^{28}$ In our case, the presence of the tumor in bilateral pleural spaces as well as the need to dissect the tumor away from the posterior mediastinum warranted the bilateral clamshell thoracotomy.

In general, the clamshell thoracotomy is rarely used in spinal surgery; however, there are instances in which the morbidity of this approach is outweighed by the benefit. For instance, Sciubba et al. reported a case of an en bloc resection of a T1-5 ventral chordoma using a 3-staged approach consisting of a posterior approach to instrument the spine, a right-sided thoracotomy to complete the cau- dal osteotomy, and a left-sided thoracotomy (with interval patient repositioning) to complete the rostral osteotomy and excise the tumor. ${ }^{9}$ Lau et al. reported the use of unilateral hemiclamshell thoracotomies to excise large spine tumors invading the mediastinum and chest cavity, but they did not report the use of bilateral hemiclamshell thoracotomies. ${ }^{29}$ The traditional formal clamshell thoracotomy does not involve an upper sternotomy. ${ }^{30}$ However, because in our patient the sternum was split for the hemiclamshell thoracotomy, the present case is technically a bilateral hemiclamshell thoracotomy (midline sternal split), not a traditional clamshell thoracotomy (no midline sternotomy). Regardless of the nomenclature, the clamshell thoracotomy allowed simultaneous access to both chest cavities and the mediastinum. Figure 5 illustrates the sequence of bony cuts (Fig. 5A), as well as the final thoracic exposure afforded by the bilateral hemiclamshell thoracotomy (Fig. 5B). Although attempts were made to access the entire tumor using a hemiclamshell thoracotomy, the contralateral chest cavity invasion precluded en bloc excision through this approach only. Intraoperative details of the steps of the approach and tumor resection are provided in Video 1. Although a morbid approach, the bilateral clamshell thoracotomy can be a useful approach in cases which require simultaneous access to both chest cavities for en bloc excision of tumors of the thoracic spine.

\section{Acknowledgments}

We would like to thank Dr. Melike Pekmezci for help interpreting the pathology specimens and Kenneth Probst for illustrations and artwork.

\section{References}

1. George B, Bresson D, Herman P, Froelich S. Chordomas: a review. Neurosurg Clin N Am. 2015;26(3):437-452.

2. Hamilton K, Rebsamen S, Salamat S, Ahmed R. Pediatric extraosseous sacral chordoma: case report and literature review of embryonic derivation and clinical implications. $J$ Neurosurg Pediatr. 2019;23(5):628-633. 
3. Inci S, Palaoğlu S, Onol B, Erbengi A. Low cervical chordoma: case report. Spinal Cord. 1996;34(6):358-360.

4. Fontes R, O'Toole JE. Chordoma of the thoracic spine in an 89-year-old. Eur Spine J. 2012;21(4)(suppl 4):S428-S432.

5. Boriani S, Bandiera S, Biagini R, et al. Chordoma of the mobile spine: fifty years of experience. Spine (Phila Pa 1976). 2006;31(4):493-503.

6. O'Neill P, Bell BA, Miller JD, et al. Fifty years of experience with chordomas in southeast Scotland. Neurosurgery. 1985; 16(2):166-170.

7. Rena O, Davoli F, Allegra G, et al. Giant chordoma of the upper thoracic spine with mediastinal involvement: a surgical challenge. Asian Spine J. 2014;8(3):353-356.

8. Reddy EK, Mansfield CM, Hartman GV. Chordoma. Int J Radiat Oncol Biol Phys. 1981;7(12):1709-1711.

9. Sciubba DM, Gokaslan ZL, Black JH III, et al. 5-Level spondylectomy for en bloc resection of thoracic chordoma: case report. Neurosurgery. 2011;69(2)(Suppl Operative):E248E256.

10. Pan Y, Lu L, Chen J, et al. Analysis of prognostic factors for survival in patients with primary spinal chordoma using the SEER Registry from 1973 to 2014. J Orthop Surg Res. 2018; 13(1):76.

11. Stacchiotti S, Gronchi A, Fossati P, et al. Best practices for the management of local-regional recurrent chordoma: a position paper by the Chordoma Global Consensus Group. Ann Oncol. 2017;28(6):1230-1242.

12. Topsakal C, Bulut S, Erol FS, et al. Chordoma of the thoracic spine-case report. Neurol Med Chir (Tokyo). 2002;42(4): $175-180$.

13. Radaelli S, Stacchiotti S, Ruggieri P, et al. Sacral chordoma: long-term outcome of a large series of patients surgically treated at two reference centers. Spine (Phila Pa 1976). 2016; 41(12):1049-1057.

14. Kortz AB. Experimental bilateral transsternal thoracotomy: factors improving survival. J Thorac Surg. 1958;35(3):305308.

15. Pasque MK, Cooper JD, Kaiser LR, et al. Improved technique for bilateral lung transplantation: rationale and initial clinical experience. Ann Thorac Surg. 1990;49(5):785-791.

16. Trulock EP, Cooper JD, Kaiser LR, et al. The Washington University-Barnes Hospital experience with lung transplantation. JAMA. 1991;266(14):1943-1946.

17. Cooper JD, Patterson GA, Grossman R, Maurer J. Doublelung transplant for advanced chronic obstructive lung disease. Am Rev Respir Dis. 1989;139(2):303-307.

18. Patterson GA, Cooper JD, Goldman B, et al. Technique of successful clinical double-lung transplantation. Ann Thorac Surg. 1988;45(6):626-633.

19. Bains MS, Ginsberg RJ, Jones WG II, et al. The clamshell incision: an improved approach to bilateral pulmonary and mediastinal tumor. Ann Thorac Surg. 1994;58(1):30-33.

20. Korst RJ, Burt ME. Cervicothoracic tumors: results of resection by the "hemi-clamshell" approach. J Thorac Cardiovasc Surg. 1998;115(2):286-295.

21. Meyers BF, Sundaresan RS, Guthrie T, et al. Bilateral sequential lung transplantation without sternal division eliminates posttransplantation sternal complications. J Thorac Cardiovasc Surg. 1999;117(2):358-364.

22. Macchiarini P, Ladurie FL, Cerrina J, et al. Clamshell or sternotomy for double lung or heart-lung transplantation? Eur J Cardiothorac Surg. 1999;15(3):333-339.
23. Shudo Y, Rinewalt D, Lingala B, et al. Impact of surgical approach in double lung transplantation: median sternotomy vs clamshell thoracotomy. Transplant Proc. 2020;52(1): 321-325.

24. Cooper JD. The evolution of techniques and indications for lung transplantation. Ann Surg. 1990;212(3):249-256.

25. Luciani GB, Starnes VA. The clamshell approach for the surgical treatment of complex cardiopulmonary pathology in infants and children. Eur J Cardiothorac Surg. 1997;11(2): 298-306.

26. Ris H-B, Banic A, Furrer M, et al. Descending necrotizing mediastinitis: surgical treatment via clamshell approach. Ann Thorac Surg. 1996;62(6):1650-1654.

27. Simms ER, Flaris AN, Franchino X, et al. Bilateral anterior thoracotomy (clamshell incision) is the ideal emergency thoracotomy incision: an anatomic study. World J Surg. 2013; 37(6):1277-1285.

28. Odell DD, Macke RA, O'Shea MA. Clamshell thoracotomy: a unique approach to a massive intrathoracic schwannoma. Ann Thorac Surg. 2011;91(1):298-301.

29. Lau D, Yarlagadda J, Jahan T, et al. Desmoplastic fibroma of the spine causing severe mediastinal compression and brachial plexus encasement: report of 2 cases. J Neurosurg Spine. 2013;19(4):515-520.

30. Panchabhai TS, Chaddha U, McCurry KR, et al. Historical perspectives of lung transplantation: connecting the dots. $J$ Thorac Dis. 2018;10(7):4516-4531.

\section{Disclosures}

The current work was supported by the UCSF Department of Neurosurgery. Dr. Chan reports receiving research support for a nonrelated study from Orthofix, Inc. Dr. Chou reports being a consultant and receiving royalties from Globus. Dr. Mummaneni reports being a consultant for DePuy Synthes, Globus, and Stryker; having direct stock ownership in Spinicity/ISD; receiving non-study-related clinical and research grant support from NREF, AO Spine, and ISSG; and receiving royalties from DePuy Spine, Thieme Publishers, and Springer Publishers.

\section{Author Contributions}

Conception and design: Burke. Acquisition of data: Burke, Chan, Mayer, Garcia, Mann, Berven, Chou, Mummaneni. Analysis and interpretation of data: all authors. Drafting the article: all authors. Critically revising the article: all authors. Reviewed submitted version of manuscript: all authors. Approved the final version of the manuscript on behalf of all authors: Burke. Statistical analysis: Burke, Mann, Berven, Chou. Administrative/technical/material support: Burke. Study supervision: Burke.

\section{Supplemental Information \\ Videos}

Video 1. https://vimeo.com/439339108.

\section{Correspondence}

John F. Burke: University of California, San Francisco, CA. john.burke@ucsf.edu. 